10IKC-146

\title{
POLYPHASE HYDROCARBON INCLUSIONS IN GARNET FROM THE MIR PIPE (YAKUTIA, RUSSIA)
}

\author{
A.V. Bovkun', A.Y. Biller ${ }^{2}$, V.L. Skvortsova ${ }^{1}$, V.K. Garanin ${ }^{1}$ \\ 1. M.V. Lomonosov Moscow State University, Moscow, Russia; \\ 2. Diamond and Precious Metal Geology Institute, Siberian Branch, Russian Academy of Sciences, Yakutsk, Russia
}

As the object of the study we specially selected a collection of garnet nodules $(3-8 \mathrm{~mm})$ of different colors, with numerous mineral and fluid inclusions from the enrichment concentrate of the kimberlite rocks in the highly diamondiferous Mir pipe (Malobotuobinsk region, Yakutia). The plane-parallel plates with a thickness of $0.8-1.8 \mathrm{~mm}$ were produced for the investigations.

The garnets from the studied collection are variously saturated with polyphase fluid and mineral inclusions, that are primarily silicate. They are so numerous in some grains that they reduce transparency of the hosting garnet. The ratio of fluid and silicate inclusions strongly varies from grains that mainly contain silicate inclusions to grains with prevailing polyphase fluid inclusions (Fig. 1, a, b, c). Many inclusions are decrepitated partially or fully and are surrounded by very fine daughter inclusions.

The polyphase fluid inclusions are uniformly distributed within the hosting mineral and are not confined to the cracks, which makes it possible to consider them as primary. Their size ranges from 20 to $100 \mathrm{im}$, but it usually does not exceed $50 \mathrm{im}$. Their structure has a gas phase in the form of the bubbles, a liquid phase of a broad color gamma ranging from colorless to different shades of brown and black) and probably a light-colored solid phase. The different combinations of the mentioned phases govern the great variety of the phase composition of fluid inclusions.
The inclusions of silicates, mainly clinopyroxene, more rarely olivine, usually form regularly oriented transparent light-green nodules that have an elongated_and short-prismatic or occasionally needle and isometric shape with a size from 10-50 to $200 \mathrm{im}$. Some garnet grains also contain oriented needle and prismatic oxide nodules (rutile and ilmenite), as well as isometrically faceted black-colored inclusions (possibly chromspinellids). The regular orientation and morphology of silicate and oxide inclusions make it possible to consider them as products of solid solution disintegration, though this question requires a further study.
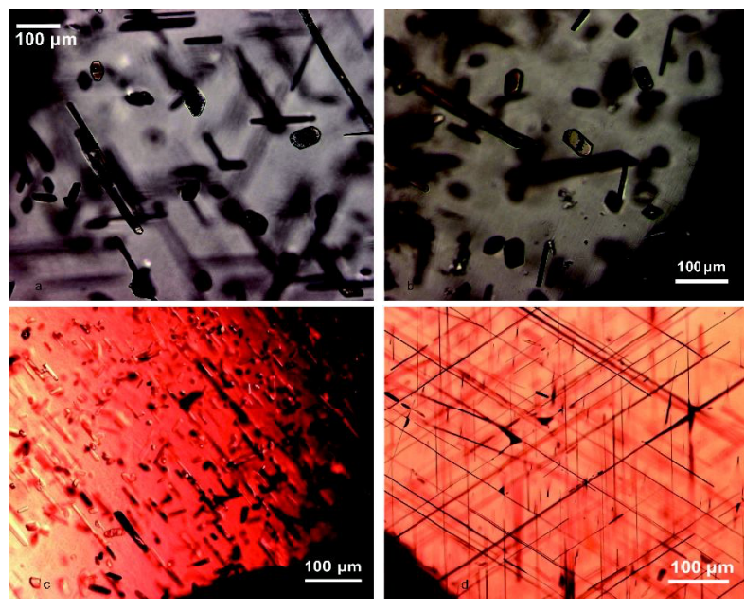

Fig. 1. The garnet grains from the Mir kimberlite pipe: $a-b$ - with dominating polyphase fluid inclusions; - with dominating regularly oriented silicate inclusions; c - with regularly oriented needle inclusions of rutile. The photo is shown in transmitted light. 


\section{$1^{\text {th }}$ International Kimberlite Conference, Bangalore - 2012}

For comparison we studied garnet grains from the Mir pipe that have numerous regularly oriented needle inclusions of rutile (Fig. 1d) and do not have apparent fluid inclusions. The rutile needles in these grains are uniformly distributed; their number and size are highly varied (the length ranges from 0.1 to $2 \mathrm{~mm}$ and the thickness, from 0.01 to $5-30 \mathrm{ìm})$.

\section{THE COMPOSITION OF THE HOSTING GARNET AND MINERAL INCLUSIONS}

The garnets with prevailing silicate and polyphase fluid inclusions exhibit the similar chemical structure and are related to pyrope (61$77 \mathrm{~mol} \%$ of $\left.\mathrm{Mg}_{3} \mathrm{Al}_{2}\left(\mathrm{SiO}_{4}\right)_{3}\right)$ with a variable quantity of almandine and grossular components (8-27 $\mathrm{mol} \mathrm{\%}$ of $\left.\mathrm{Fe}_{3} \mathrm{Al}_{2}\left(\mathrm{SiO}_{4}\right)_{3}\right)$ and 5-19 $\mathrm{mol} \mathrm{\%}$ of $\left.\mathrm{Ca}_{3} \mathrm{Al}_{2}\left(\mathrm{SiO}_{4}\right)_{3}\right)$, respectively. Their composition is characterized by a low content of chrome (usually $0.10-1.74$, in rare cases up to $2.96 \mathrm{wt} \%$ $\left.\mathrm{Cr}_{2} \mathrm{O}_{3}\right)$, titanium $\left(0.01-0.06 \mathrm{wt} \% \mathrm{TiO}_{2}\right)$, sodium (usually $0-0.06$, in a few cases up to $0.24 \mathrm{wt} \%$ $\mathrm{Na}_{2} \mathrm{O}$ ) and practically complete absence of $\mathrm{Fe}^{3+}$ (Fig. 2). The content of magnesium, aluminum, silicon, and especially iron varies within a comparatively wide range (17.1-21.9 of $\mathrm{wt} \%$ $\mathrm{MgO} ; 3.7-8.8$ of $\mathrm{CaO} ; 21.7-24.8$ of $\mathrm{Al}_{2} \mathrm{O}_{3} ; 39.9-$ 44.5 of $\mathrm{SiO}_{2} ; 4.2-14.6$ of $\mathrm{FeO}$ ).

It is quite interesting that the majority of garnets that are saturated with silicate and polyphase fluid inclusions have an increased content of silicon ( $\mathrm{Si}>3$ formula units) in terms of crystal-chemical coefficients. Gasparik (2002) proposed to classify the grossular-almandinepyrope series garnets that have over 3.03 formula units of Si to the majoritic type, taking errors during microprobe analysis into account. In general, about $40 \%$ of the studied garnets with silicate and fluid inclusions conform to this condition ( $\mathrm{Si}=3.031-3.084$ formula units).

Clinopyroxene is characterized by a high content of magnesium and calcium (16.7-18.1 $\mathrm{wt} \% \mathrm{MgO} ; 21-23.3 \mathrm{CaO})$ and a low content of chrome, aluminum, iron, and sodium (0.2-0.7 $\mathrm{Cr}_{2} \mathrm{O}_{3} ; 0.7-2.5 \mathrm{Al}_{2} \mathrm{O}_{3} ; 1.1-1.5 \mathrm{FeO} ; 0.4-1.7 \mathrm{Na}_{2} \mathrm{O}$. According to the compositional analysis it is referred to diopside (77.4-66.1 mol \% $\mathrm{CaMgSi}_{2} \mathrm{O}_{6}$ ) with an admixture of the following components: jadeite (2.8-11.8 mol \% $\mathrm{NaAlSi}_{2} \mathrm{O}_{6}$ ), clinoenstatite (4.6-7.1 mol \% $\mathrm{Mg}_{2} \mathrm{Si}_{2} \mathrm{O}_{6}$ ) and hedenbergite (3.2-4.5 mol \% $\left.\mathrm{CaFeSi}_{2} \mathrm{O}_{6}\right)$. The olivine inclusions are represented by forsterite (95.2-96 mol \% $\mathrm{Mg}_{2} \mathrm{SiO}_{4}$ ) with a low content of iron (4.7-4.8 of wt $\% \mathrm{FeO}$ ) and chrome (up to 0.1 $\mathrm{wt} \% \mathrm{Cr}_{2} \mathrm{O}_{3}$ ).

The rare elongated inclusions of oxides consist of ilmenite and rutile. Ilmenit is represented by $\mathrm{Cr}$-containing picroilmenite with a low content of ferric iron (13-13.2 of wt $\% \mathrm{MgO}$; 55.4-55.8 $\mathrm{TiO}_{2} ; 1.4-1.5 \mathrm{Cr}_{2} \mathrm{O}_{3} ; 0.2-0.3 \mathrm{Al}_{2} \mathrm{O}_{3}$; and 2-2.7 $\mathrm{Fe}_{2} \mathrm{O}_{3}$ ); its composition is close to picroilmenite from the inclusions in diamond and diamondiferous peridotites. The rutile composition is usually characterized by the constant presence of iron admixture $(0.7-1.3 \mathrm{wt} \%$ $\mathrm{FeO})$ at a low content chrome, aluminum, and magnesium, single nodules of rutile exhibit a markedly increased content of the latter (up to 3.9 $\mathrm{wt} \% \mathrm{Cr}_{2} \mathrm{O}_{3} ; 1.3 \mathrm{Al}_{2} \mathrm{O}_{3}$; and $1.2 \mathrm{MgO}$ ).

In most cases the garnets that are abundantly saturated with regularly oriented needle inclusions of rutile and that do not contain visible fluid inclusions differ in their chemical composition from the garnets with dominating silicate and/or polyphase fluid inclusions by a higher content of chrome (usually 1.5-3.7, more rarely $0.3-0.4 \mathrm{wt} \%$ $\mathrm{Cr}_{2} \mathrm{O}_{3}$ ), titanium and sodium (usually $0.09-0.22$ $\mathrm{wt} \% \mathrm{TiO}_{2} ; 0.04-0.06 \mathrm{Na}_{2} \mathrm{O}$ ) and they do not often have a content that is similar to the last ones (Fig. 2). The increased content of silicon ( $\mathrm{Si}>3$ formula units) is not typical of such garnets. Rutile that forms numerous needle nodules is often characterized by an increased content of chrome (up to $4.2 \mathrm{Cr}_{2} \mathrm{O}_{3}$ ), whereas the admixtures of iron and other elements occur in quite small quantities (0.2-0.5 wt\% FeO; 0.06-0.3 $\mathrm{Al}_{2} \mathrm{O}_{3}$; and $0-0.06$ $\mathrm{MgO})$. 


\section{$1^{\text {th }}$ International Kimberlite Conference, Bangalore - 2012}

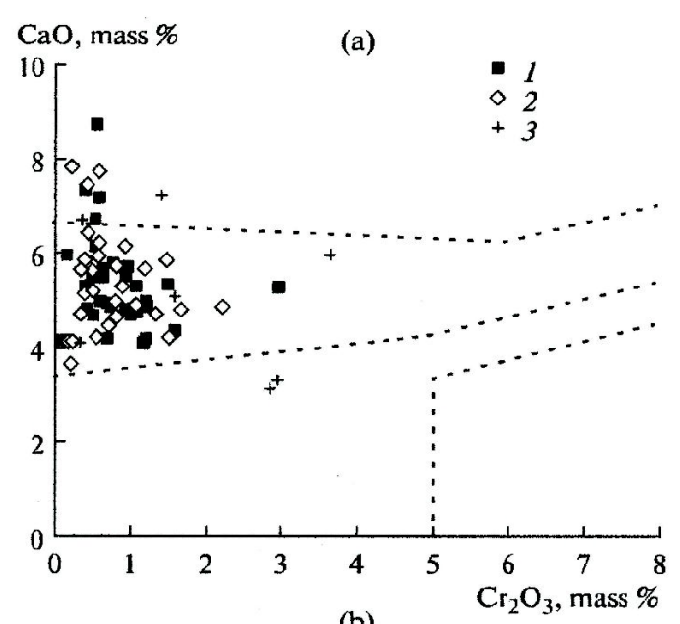

(b)

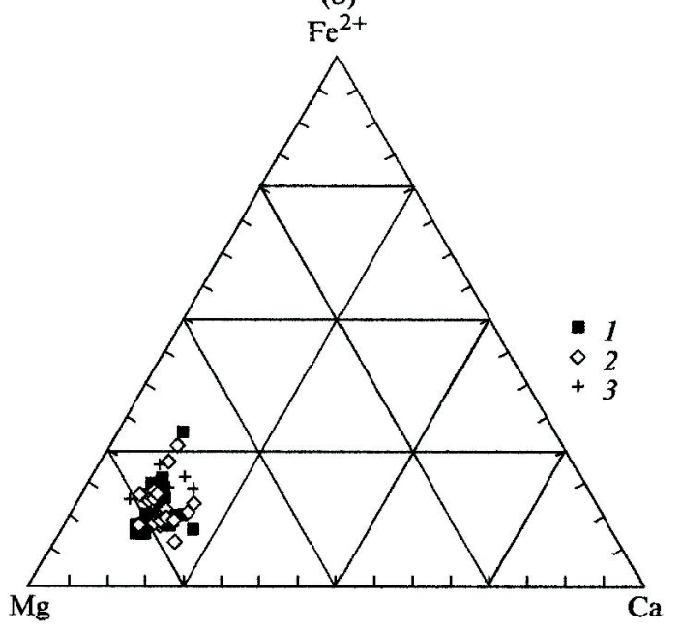

Fig. 2. The composition diagram for the garnet from the Mir kimberlite pipe: 1 - with dominating polyphase fluid inclusions; 2 with dominating regularly oriented silicate inclusions; 3 - with regularly oriented needle inclusions of rutile.

\section{THE STUDY OF POLYPHASE FLUID INCLUSIONS}

The polyphase fluid inclusions were studied by IR-Fourier- and Raman-spectroscopy methods. The IR spectra of fluid inclusions were obtained using a one-beam Avatar 360 IR-Fourier spectrometer and the Continium microscope produced by Nicolet Company. The Raman spectra were measured by the JOBIN YVONU1000 spectrometer using $\mathrm{He}-\mathrm{Cd}$ (blue) and $\mathrm{Ar}-\mathrm{Kr}$ (red) lasers.
IR-Fourier spectroscopy. Figs 3-4 show the most typical inclusions and their IR spectra. We should mention that the IR spectra were obtained for the largest inclusions; nevertheless, the focus of the spectrometer beam often displayed a mixture of phases.
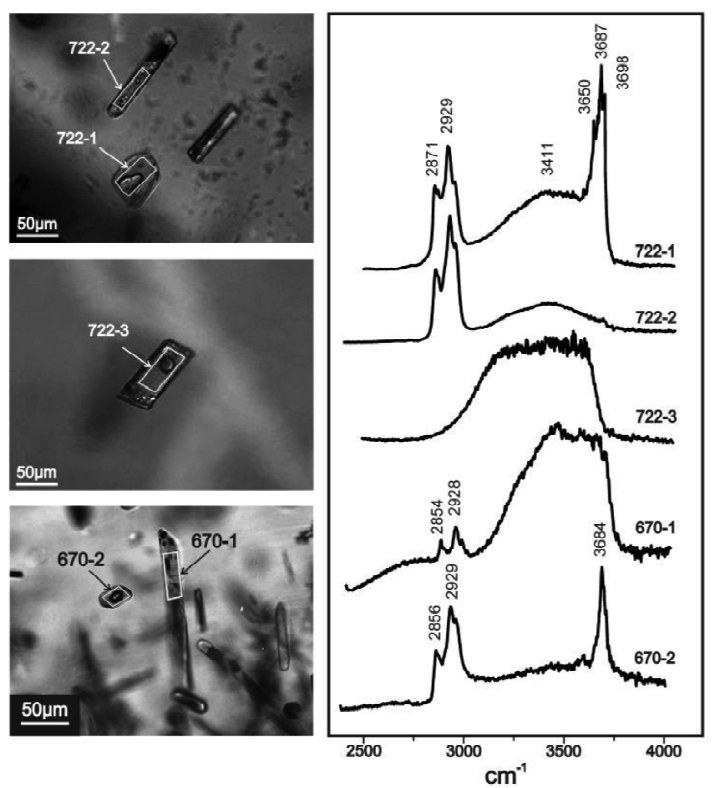

Fig. 3. The polyphase fluid inclusions in the garnet from the Mir kimberlite pipe and their respective IR spectra (samples 722 and 670 ). The solid line in the photo designates the focus of the spectrometer beam.

The IR spectroscopy data indicate the complex phase composition of fluid inclusions. The spectra of all inclusions under study exhibit absorption bands in the range from 2850-3020 $\mathrm{cm}^{-1}$ and a wide band in the range from

$3100-3600 \mathrm{~cm}^{-1}$. The bands in the domain of $2860-3020 \mathrm{~cm}^{-1}$ usually occur due to the presence of hydrocarbons (Glebovskaya, 1971; Titus et al., 2005). The primary fluid inclusions, which contain mixtures of highmolecular weight hydrocarbons (HMHs) by the data of IR-Fourier spectroscopy are found in the garnets from diamondiferous eclogites of the Udachnaya and Mir kimberlite pipes (Tomilenko, 2006; Tomilenko et al., 2009). The absorption peaks are 


\section{$1^{\text {th }}$ International Kimberlite Conference, Bangalore - 2012}
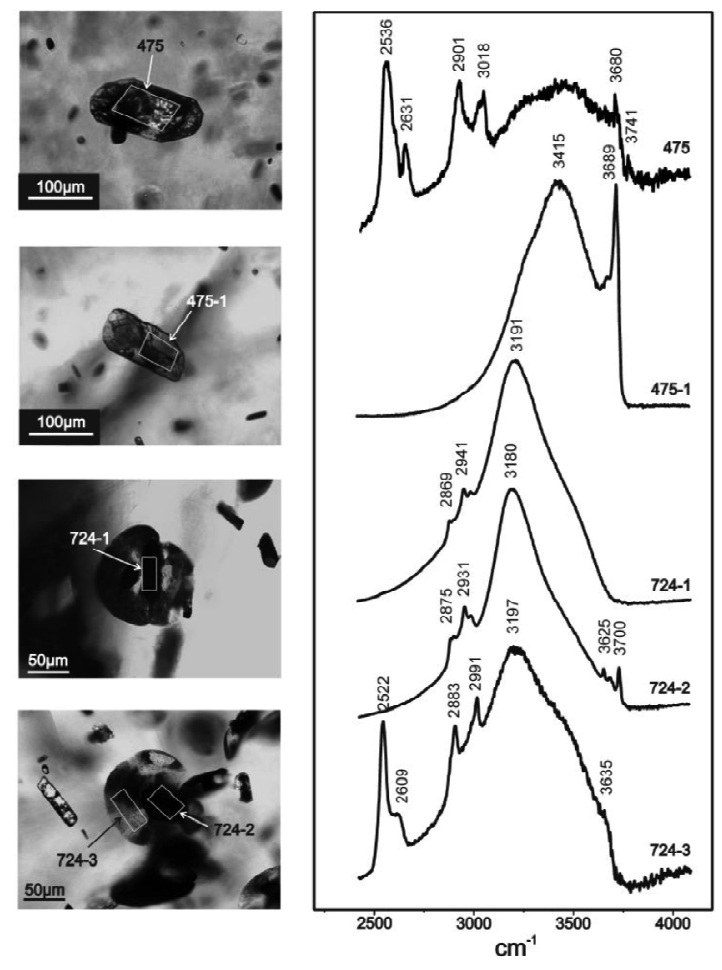

Fig. 4. Polyphase fluid inclusions in the garnet from the Mir kimberlite pipe and their respective IR spectra (samples 475 and 724).

not established by these authors in the other frequency domains.

The IR-absorption spectra of chloroform extracts from garnets that are saturated with hydrocarbon inclusions and are taken from the Mir kimberlite pipe by the data (Krot, 1985) also showed lines in the domain of $3000 \mathrm{~cm}^{-1}$ (2905 and $2840 \mathrm{~cm}-1)$. The occurrence of polyaromatic hydrocarbons (PAHs) was found in these extracts.

It is known that the lower frequency range $\left(2000-500 \mathrm{~cm}^{-1}\right)$ of the IR spectra is quite informative when identifying high_molecular weight compounds; however, due to the absorption of the hosting garnet, it cannot be observed. Nevertheless, it is known that the absorption bands in the frequency domain of $3020-2860 \mathrm{~cm}^{-1}$ are a typical component of the IR spectra of solid and viscous bitumens whose main constituents are PAHs (Syngaevskii et al., 2007).

The IR spectra of several inclusions in our study displayed narrow peaks in the range of 2500 $\mathrm{cm}^{-1}$ that are probably also caused by the presence of $\mathrm{CO}_{2}$. In the opinion of A.A. Tomilenko (2006), the narrow band of absorption in the domain of $2500 \mathrm{~cm}^{-1}$ in the IR spectra of fluid inclusions in natural diamonds of the $\mathrm{V}$ category according to the classification by Yu.L. Orlov may indicate their substantially carbon dioxide composition.

We should mention that the bands of absorption in the domains of $3700 \mathrm{~cm}^{-1}$ (spectra $722-1$ and 660-2 in Fig. 3) and $2500 \mathrm{~cm}^{-1}$ (spectra 475 and $724-3$ in Fig. 4) require more detailed identification.

The displacement of typical absorption bands is most likely caused by a complex composition of polyphase inclusions. For example, the water component of inclusions can be saline solutions of different concentration.

Raman spectroscopy. Raman spectroscopy is the most widely used nondestructive method used to study inclusions; however, it limits the studies of hydrocarbon inclusions because of the strong fluorescence of the latter. Therefore, in our case we used it mainly to reveal the differences in the Raman spectra of the garnets with various types of inclusions.

As a result, we established that the garnets with abundant inclusions of rutile are not luminescent (Fig. 5a, is spectrum 2), which means that they do not contain hydrocarbon inclusions. The garnets with dominating silicate inclusions exhibited weak luminescence (Fig. 5a, spectrum 1), which revealed the presence of an insignificant quantity of inclusions with a hydrocarbon component.

The Raman spectra of the garnets with numerous substantially hydrocarbon polyphase inclusions provide an ascending spectrum in a wide domain up to $4000 \mathrm{~cm}^{-1}$ when using a blue (He-Cd) laser (Fig 5b shows spectrum 1). The replacement of the blue laser with a red $(\mathrm{Ar}-\mathrm{Kr})$ 


\section{$1^{\text {th }}$ International Kimberlite Conference, Bangalore - 2012}

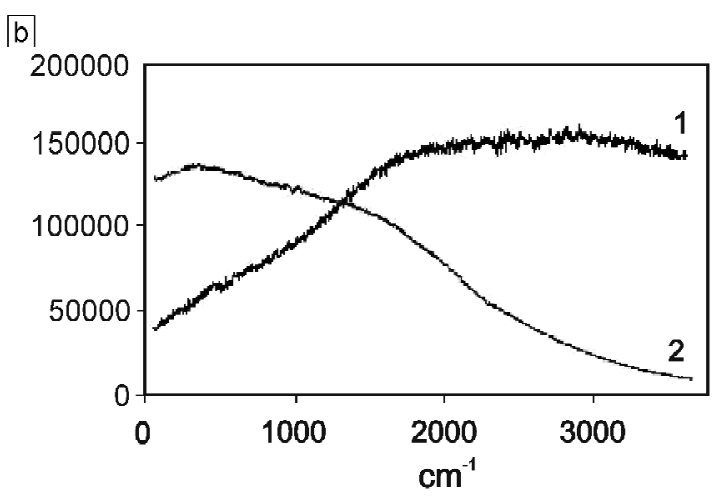

Fig. 5. The Raman spectra of the garnets from the Mir kimberlite pipe: a with numerous inclusions of silicates (1) (sample 661) and rutile (2) (sample 335); b with substantially hydrocarbon polyphase inclusions, sample 722 ( 1 is the $\mathrm{He}-\mathrm{Cd}$ laser and 2 is the $\mathrm{Ar}-\mathrm{Kr}$ laser).

one made it possible to establish the domain with the ascending spectrum (Fig. $5 \mathrm{~b}$ shows spectrum 2). Thus, we found the domain of the Raman spectrum that characterizes the presence of a considerable quantity of polyphase inclusions with a content of hydrocarbons.

For the substantially hydrocarbon fluid inclusions in the garnet from xenolith in diamondiferous eclogite of the Udachnaya kimberlite pipe, the Raman spectra have the similar shape of an ascending hump, although this is recorded only to $1200 \mathrm{~cm}^{-1}$ (Tomilenko, 2006).

In (Zhang et al., 2007), which is dedicated to the study of the Raman spectra of individual hydrocarbons and hydrocarbon inclusions in various minerals, the data suggest

that normal and branched hydrocarbons (C5-C13) have a rich spectrum in general, but with similar typical absorption bands, whereas aromatic hydrocarbons exhibit strong luminescence and a wide fuzzy spectrum within the entire domain (from 0 to $5000 \mathrm{~cm}^{-1}$ ). Due to investigation of numerous hydrocarbon inclusions $(>1000)$, the authors of the above mentioned work discovered five types of Roman spectra, but only one of them was similar to the spectra of aromatic hydrocarbons and to the Roman spectra that were obtained for the garnets from our collection (Fig. 6). This indicates that the polyphase fluid inclusions in our study consist of polyaromatic hydrocarbons.

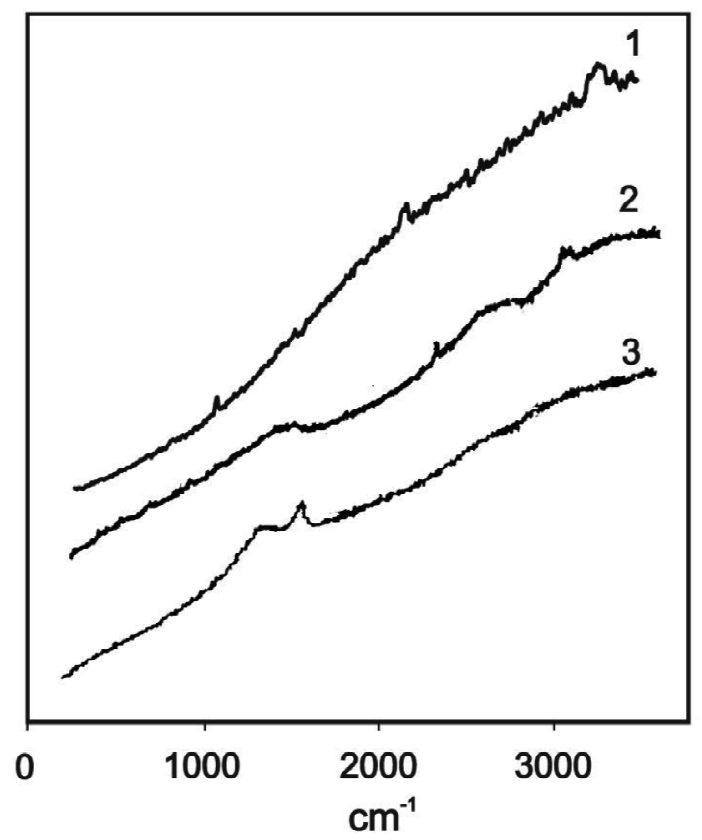

Fig. 6. The Raman spectra of several components of oil ( $l$ is aromatic hydrocarbons, 2 is bitumens) according to Zhang et al., (2007) and garnet with numerous substantially hydrocarbon polyphase inclusions from the Mir kimberlite pipe (3), sample 670.

\section{DISCUSSION}

These investigations showed that the garnet nodules from the Mir kimberlite pipe have several unique features: their chemical composition, a high degree of saturation with primary polyphase fluid and regularly oriented mineral inclusions.

According to their composition, garnets belong to the grossular-almandine-pyrope series. Some of them have features that are similar to garnets from xenoliths of peridotite (lherzolite and websterite) and eclogite paragenesises, as well as inclusions in a diamond. The majority of garnets have a specific composition (an increased content of $\mathrm{Si}, \mathrm{Mg}, \mathrm{Al}$, and the absence of $\mathrm{Fe} 3+$ ) and do not have complete analogs among the garnets from the xenoliths discovered in deep_seated rocks. An 


\section{0 $^{\text {th }}$ International Kimberlite Conference, Bangalore - 2012}

increased content of silicon $(\mathrm{Si}=3.031-3.084$ formula units) may indicate the possible occurrence of a certain quantity of a majoritic component in these garnets and the absence of $\mathrm{Fe}^{3+}$ may point to their formation under reducing conditions.

It is especially interesting that garnets with polyphase fluid inclusions have different saturation levels of clinopyroxene inclusions, more rarely with olivine, ilmenite, and rutile inclusions; their regular orientation and morphology indicate that they formed as a result of the disintegration of a solid solution of a garnet of a more complex composition. Garnets of a similar composition that contain clinopyroxene (omphacite) inclusions oriented along the plane of a hosting garnet have been described for eclogite xenoliths from the Jagersfontein kimberlite pipe (Republic of South Africa) (Hargerty and Sautter, 1990) and for inclusions in the diamonds from the Juina province (Brazil) (Harte and Cayzer, 2007). The authors of the above works believe that clinopyroxene lamellae form due to disintegration of a solid solution of a high bar majoritic garnet, which is confirmed by the calculations of the primary content of the garnet.

The nondestructive methods of IR-Fourier and Raman spectroscopy showed that polyphase fluid inclusions are polyaromatic hydrocarbons, water solutions, and $\mathrm{CO}_{2}$. The presence of combined inclusions of high density water-salt fluid with hydrocarbon phases was established earlier for this garnet collection during microthermometric research (Prokof'ev et al., 2008a). The fluorescence microscopy method revealed a fluorescence spectrum for the organic substance of complex structure within the range of exciting light wavelengths of 450-490 nm (Prokof'ev et al., 2008b). In the opinion of the authors, these data indicate the simultaneous capture of both aqueous fluid and hydrocarbons and the complex chemical composition of the hydrocarbon component of these inclusions.

\section{CONCLUSIONS}

Thus, the results obtained using different methods during the study of the garnet inclusions from the collection in question indicate that the garnet crystallized in a medium saturated with hydrocarbon-containing fluids of complex composition. We should mention that the composition of polyphase inclusions is a product of fluid evolution. The evolution processes in garnets and fluids are probably interconnected.

Several scientists (Navon et a1., 2008; Stachel et al., 2008) have proposed a model for global evolution of fluids. They found different sources of deep-seated fluids and established various possible stages of their evolution, viz., the open process of fractionating, mixing with newly entering fluids, the interaction with mantle rocks, etc.

The specific distribution of rare and rareearth elements in microinclusions in diamond crystals with tangential and normal growth mechanisms indicated that two different types of fluids are involved in their formation, in which case $\mathrm{C}-\mathrm{H}-\mathrm{O}$ containing fluids play a special role in the diamonds with a tangential growth mechanism (Araujo et al., 2008).

We should emphasize that it is of fundamental importance that exactly polyaromatic hydrocarbons have been proven to occur in polyphase fluid inclusions. A.P. Rudenko et al. (1993) assumed that diamond formation may be a complex process in the background of aromatic polycondensation from light carbon-containing molecules $\left(\mathrm{CH}_{4}, \mathrm{CO}\right.$, and $\mathrm{CO}_{2}$ in the fluid state).

The problems of diamond genesis and deep mineral formation are disputable in many respects; however, the participation of fluids in these processes undoubtedly plays a large role.

\section{References}

Araujo, D.P., Griffin, W.L., and O'Reilly, S.Y. (2008) Microinclusions in Monocrystalline Octahedral Diamonds from Diavik, Slave Craton: Clues To 


\section{$10^{\text {th }}$ International Kimberlite Conference, Bangalore - 2012}

Diamond Genesis, 9th Int. Kimberlite Conf, Ext. Abstr. no. 9IKC_A_000138.

Gasparik, T. (2002) Experimental Investigations of the Origin of Majoritic Garnet Inclusions in Diamonds, Phys.Chem. Minerals, v.29, pp. 170-180.

Glebovskaya, E.A. (1971) Primenenie infrakrasnoi spektroskopii v neftyanoi geokhimii (The Use of Infrared Spectros copy in Oil Geochemistry), Leningrad: Nedra.

Haggerty, S.E. and Sautter, V. (1990) Ultra_Deep (>300 Km), Ultramafic Upper Mantle Xenoliths, Science, v. 248, pp. 993-996.

Harte Â. and Cayzer N. (2007) Decompression and Unimixing of Crystals Included in Diamonds from the Mantle Transition Zone, Phys. Chem. Minerals, v. 34, pp. 647-656.

Krot, A.N. (1985) Mineral Inclusions in Garnets from Kimberlite Pipes in the Malobotuobinsk Region, Their Genetic and Applied Meaning, Ext. Abstr. Of Cand. Sci. Diss., Moscow State Univ., Moscow.

Navon, O., Klein_BenDavid O., Logvinova A., et al. (2008) Yakutian Diamond_Forming Fluids the Evolution of Carbonatitic High_Density Fluids, 9th Int. Kimb. Conf, Ext. Abstr. no. 9IKC_A_00120.

Prokof'ev, V.Yu., Garanin, V.K, and Biller, A.Ya. (2008) Inclusions of High Density Water Fluid in Pyropes of the Mir Kimberlite Pipe (Yakutiya, Russia), in Proc.of XIII Int. Conf. on Thermal Barochemistry and IV ARIFIS Symp., Moscow: IGEM RAN, v.1, pp. 143-144.

Prokof'ev, V.Yu., Koshkin, A.V., Selektor, S.L., et al. (2008) Possibilities of Fluorescence Microscopy of Organic Substance of Fluid Inclusions in Minerals (-2-),v.1, pp. 47-49.
Rudenko, A.P., Kulakova, A.A., and Skvortsova, V.L. (1993) Chemical Synthesis of Diamond: Aspects of General Theory, Usp. Khim., , v. 62, no. 2, pp. 99-117.

Stachel Ò., Harris J.W., and Muehlenbachs Ê. (2008) Sources of Carbon in Inclusion Bearing Diamonds, 9th Int. Kimb.Conf, Ext. Abstr. no. 9IKC_A_00132.

Syngaevskii, E.D., Shchegol'kov, Yu.V., Vitozhents, G.Ch, et al. (2007) Isotope_Geochemical Features of Transformation of Coals and Bitumens under Formation of Different Types of Ore Mineralization. Report 1. Isotope Geochemical Features of Structural Transformation of Coals and Bitumens, Litol. Polezn. Iskop., no. 5, pp. 468-485.

Titus, E., Misra, D.S., Sikder, A.K., et al. (2005) Quantitative Analysis of Hydrogen in Chemical Apor Deposited Diamond Films, Diamond and Related Materials, no. 14, pp. 476-481.

Tomilenko, A.A. (2006) Fluid Regime of Mineral Formation in Continental Lithosphere at High and Moderate Pressures from the Data of Studying Fluid and Melt Mineral Inclusions, Ext. Abstr. of Doctoral Dissertation, Irkutsk.

Tomilenko, A.A., Kovyazin, S.V., Pokhilenko, L.N., and Sobolev, N.V. (2009) Primary Hydrocarbon Inclusions in Garnet of Diamond-Bearing Eclogite from the Udachnaya Kimberlite Pipe, Yakutiya, Dokl. Akad. Nauk, 2009, v. 426, no. 4, pp. 533536.

Zhang, N., Tian, Z., Leng, Y., et al. (2007) Raman Characteristics of Hydrocarbon and Hydrocarbon Inclusions, Science in China. Ser. D: Earth Sci, v. 50, no. 8, pp. 1171-1178. 